\section{International Scientific Journal Theoretical \& Applied Science}

\author{
p-ISSN: 2308-4944 (print) e-ISSN: 2409-0085 (online) \\ Year: $2016 \quad$ Issue: 2 Volume: 34 \\ Published: 29.02.2016 http://T-Science.org
}

SECTION 3. Nanotechnology. Physics.
Manat Beyshenovich Tlebayev

Doctor of engineering sciences, Professor, Academician of Kazakh National Academy of

Natural Sciences, Head of the department

"Computer engineering and Informatics"

Taraz State University named after M.Kh. Dulati,

Kazakhstan

Pavel Nikolayevich Shevtsov

master student

Taraz State University named after M.Kh. Dulati,

Kazakhstan

pashka_111@bk.ru

\title{
THE EFFECT OF CARBON NANOTUBES ON THE PROPERTIES OF COMPOSITE MATERIALS BASED ON PLASTIC
}

\author{
Abstract: The article presents a review of modern technologies of forming of composite materials with \\ different fillers. \\ Key words: polyether matrix, carbon nanotubes, functionalization, composite material, nanocomposite, \\ ultrasonic homogenization \\ Language: Russian \\ Citation: Tlebayev MB, Shevtsov PN (2016) THE EFFECT OF CARBON NANOTUBES ON THE \\ PROPERTIES OF COMPOSITE MATERIALS BASED ON PLASTIC. ISJ Theoretical \& Applied Science, 02 \\ (34): 89-92. \\ Soi: http://s-o-i.org/1.1/TAS-02-34-15 Doi: crossef http://dx.doi.org/10.15863/TAS.2016.02.34.15

\section{ВЛИЯНИЕ УГЛЕРОДНЫХ НАНОТРУБОК НА СВОЙСТВА КОМПОЗИЦИОННЫХ МАТЕРИАЛОВ НА ОСНОВЕ ПЛАСТИКА}

Аннотация: В статье представлен обзор современных технологий формирования композищионных материалов с различными наполнителями.

Ключевые слова: полиэфирная матрища, углеродные нанотрубки, функционализация, композитный материал, нанокомпозит, ультразвуковая гомогенизация.

В современной науке и производстве наноматериалы стали играть важную роль. Они стали объектом исследования в связи с ожиданием их промышленного использования уникальных свойств и качеств, и в особых проблемах интерпретаций свойств наноразмерных систем. В связи с очень малыми размерами частиц требуется создать новые и эффективные инструментальные средства проведения виртуальных и эмпирических экспериментов. Огромное количество атомов в структуре нанотрубки необходимые для контроля и учета при проектировании композиционных материалов, влияют на проектирование и адекватные результаты решения различных задач. В связи с невозможностью создания идеальных и идентичных нанотрубок встает вопрос о принятии во внимание этих дефектов (производства нанотрубок и энтропии компонентов) и учитывание их в модели. Увеличение количества и различных пространственных форм нанотрубок и их дефектов в стремлении детализировать композиционный материал в определенный момент времени приводит к недостатку вычислительных ресурсов и нет возможности произвести измерения и расчеты задачи. Возможность качественно произвести расчеты зависит от используемого расчетного метода, одними из наиболее сложными являются квантомеханические методы, сравнительно легкими - молекулярная механика.

Порошкообразные образцы МCHT представляют совокупность агломератов, размер которых колеблется от 10 до 100 мкм [2]. По данным ТЕМ внутренняя структура агломератов представляет спутанные пучки многостенных трубок и нановолокон. Присутствует также в небольшом количестве аморфный углерод. Образцы неоднородны как по структуре, так и по содержанию дефектов. Каждая из структурных единиц обладает собственной дефектностью. 


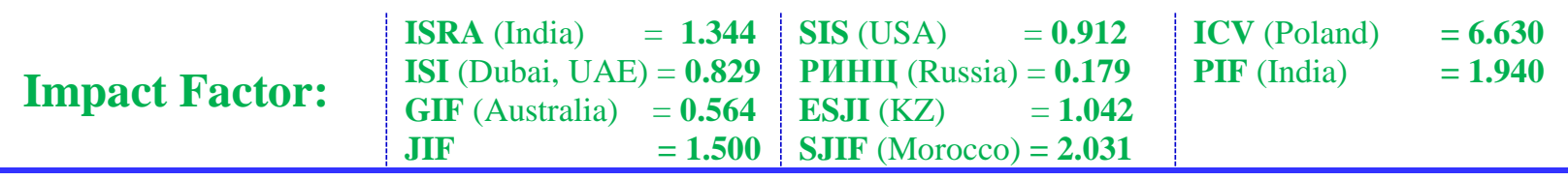
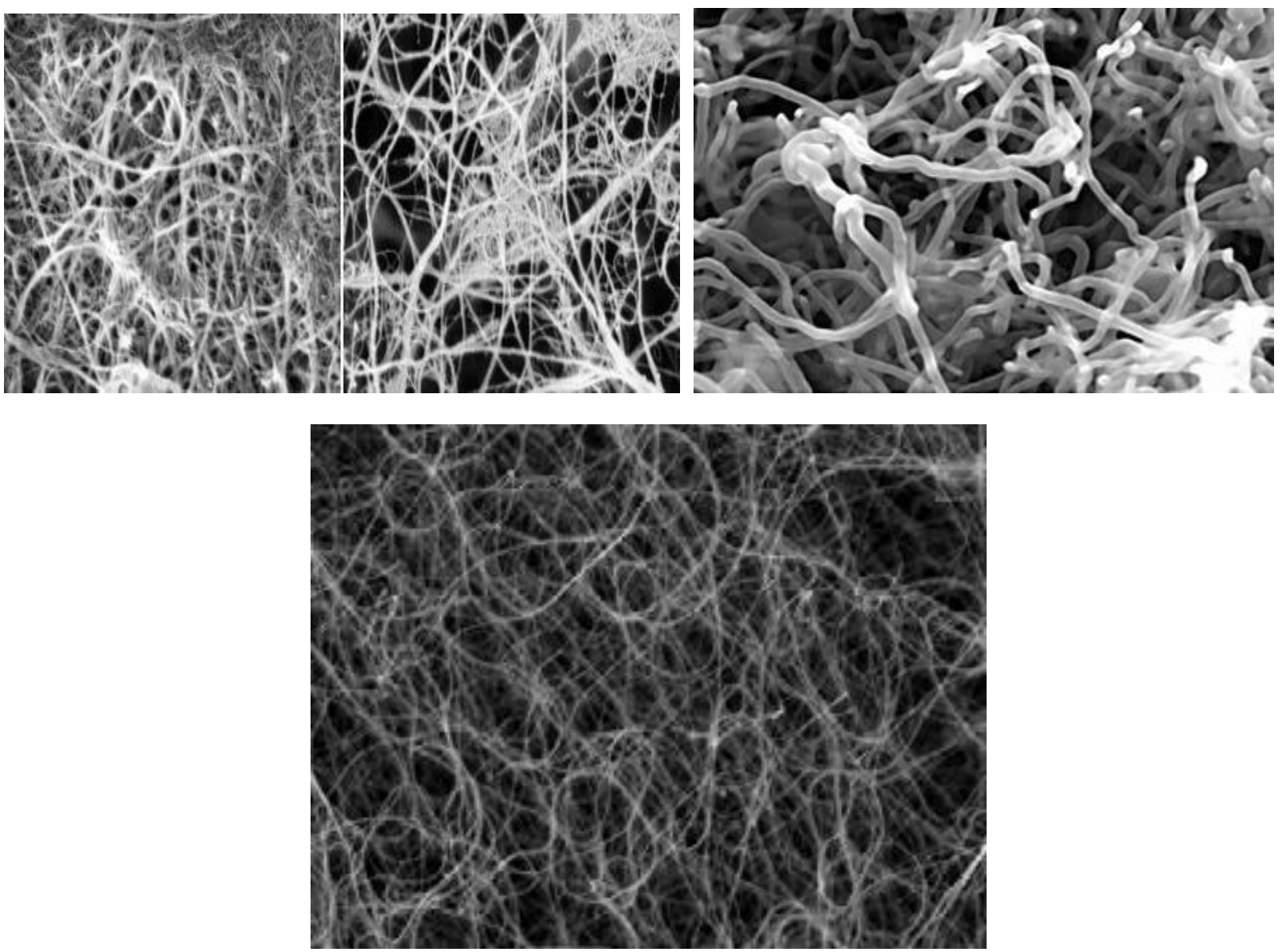

Рисунок 1 - Пример спутанных пучков нанотрубок и нановолокон.

Учеными Е.А. Воробьевым, К.Е. Бачуриным, А.В. Макунином и Н.Г. Чеченином исследуются материалы с включениями наночастиц в их состав, исследуются затруднения, связанные с их применением. К примеру, когломераты, препятствующие одинаковому распределению в матрице, образование в результате их применения. Они не позволяют достичь ожидаемого эффекта. Авторами выявлена характерная зависимость между свойствами материала и размерами частиц дисперсионной фазы. Помимо этого, с увеличением содержания наполнителя увеличивается их охрупчиваемость. В работе были сделаны несколько значительных выводов, к примеру, то, что нано трубки важно активизировать в смеси с определенными органическими смесями, и процентное содержание их не должно превышать одного процента [3].

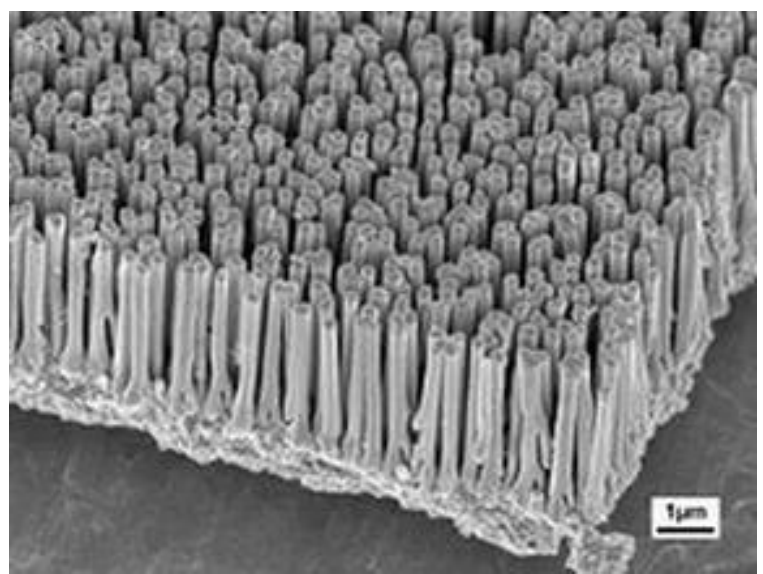

Рисунок 2 - Выращивание относительно однородных нанотрубок.

ISPC Technology and Innovation,

Philadelphia, USA 
Размерность данных нанотрубок составляет: радиус цилиндра нанотрубки варьируется от 10 до 100 нм, длина нанотрубки, принимает значения от 20 до 200 нм [4].

Размер агломератов НТ составляет от 1 до 50 мкм. До испергирования размер агломератов достигал 0,5 мм и более [5].

Изделия на пластической основе производят весьма разнообразными методами. Метод изготовления изделия обусловлен видом полимера, его исходным состоянием, а также конфигурацией, формой и его габаритами.

Изделия из расплавов или растворов термопластичных полимеров изготавливают экструзией (непрерывное выдавливание расплава), литье под давлением (заполнение расплавом полости формы), выдуванием (для пустотелых изделий), спеканием, напылением и т.д.

Наиболее приемлемую классификацию предложил Мак-Келви.

В основу этой классификации положено категорирование методов, основанное на протекании только физических процессов; методов формообразования, которые заканчиваются химическим превращением и комбинированные методы, в которых протекают и физические, и химические превращения.

В первую группу объединены такие методы, как экструзия, каландрование (течение между валками), литье под давлением, т.к. в процессе формообразования протекают физические превращения.

В качестве исходного сырья используют гранулированные композиции на основе термопластичных полимеров. Вторая группа методов переработки (спекание, окунание) имеет общие процессы. Здесь изделия изготавливаются из порошкообразной пасты с последующим спеканием.

Для последней группы характерны общие закономерности протекания реакций поликонденсации или полимеризации. Мономер смешивают с инициатором или катализатором, заливают в жидком виде в форму, где вследствие химической реакции происходит образование полимера. [6]

Наиболее распространенные методы переработки представлены на рис. 3.

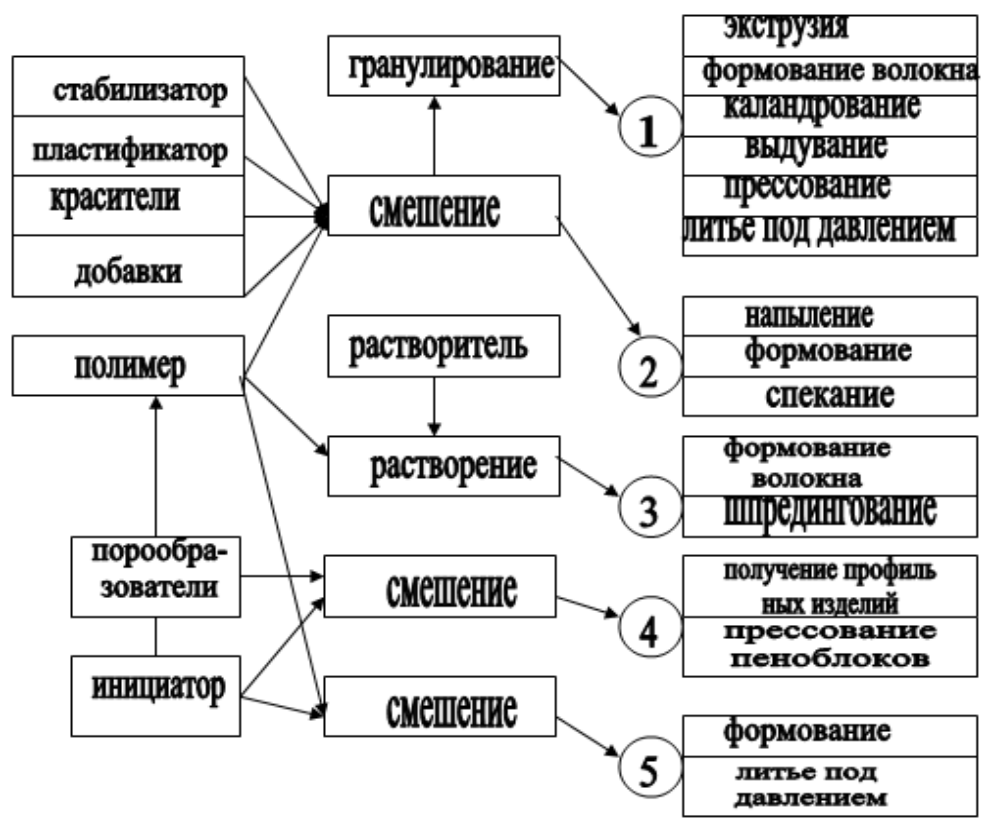

Рисунок 3 - Основные методы переработки композиционных материалов.

\begin{abstract}
Полимеры, наполненные различными микрочастицами, позволяют уменьшить содержание полимеров в композите.

Впервые такие полимеры были представлены в 70х годах. В своей структуре они содержали оксид кремния с различными размерами частиц от 0,01 до 0,06 мкм. Такой не значительный размер наполнителя, на много меньше толщины готового продукта, это позволяет дополнительно отполировать
\end{abstract}

поверхность готового продукта в случае необходимости.

При увеличении количества наполнителя необходимо учитывать и количество полимера, которое потребуется для смачивания поверхности наполнителя.

При необходимости увеличения процента содержания наполнителя в композите применяется двухстадийная технология его введения в композит. На первом этапе готовится 
материал с чрезвычайно высоким содержанием наполнителя, после чего он полимеризуется и измельчается. Предполимеризованные частицы добавляются на втором шаге в виде наполнителя в полимерную матрицу.

Гибридные композиты содержат частицы размерами от 14 до 20 мкм, а также мелкие частицы кремния от 0,009 до 0,06 мкм. Но их свойства во многом зависят от крупных частиц наполнителя [7].

Прочность композита во многом зависит от прочности сцепления наполнителя и матрицы, это достигается адсорбцией и химическим воздействием, тем самым несколько не совместимых компонентов взаимодействуют между собой.

По мимо всего наполнитель может и не оказывать никакого воздействия на прочность или другие свойства готового композита. Таким наполнителем бывает инертный. Активный в свою очередь существенно меняет свойства. Названия композитов исходит из названий его наполнителей.

Связующее вещество становится одним из важнейших компонентов в композитных материалах. Оно позволяет на полную использовать все физико-химические характеристики составных частей матриц и наполнителей.

\section{References:}

1. Baytinger EM, Vekesser NA, Kovalev IN, Bekhterev AN, Viktorov VV (2012) Osobennosti stroeniya mnogosloevykh uglerodnykh nanotrubok. Avt. UDK:539.2.541.1 Vestnik YuurGU, №11, 2012.

2. Baytinger EM, Vekesser NA, Kovalev IN (2011) Issledovanie mnogosloevykh uglerodnykh nanotrubok metodom kompleksnoy prosvechivayushchey elektronnoy mikroskopii. Neorganicheskie materialy. 2011. T.47, №6 pp.614-617.

3. Kozlov GV, Burya AI (2008) Reports of the National Academy of Sciences of Ukraine, 2008, №1. ISSN 1025-6415.

4. Bochkareva LV, Sanikovich DM (2013) Komp'yuternoe modelirovanie svoystv materialov, ukreplennykh uglerodnymi nanotrubki. UDK 658.512.011.56. Belorusskiy gosudarstvennyy universitet informatiki i radioelektroniki P. Brovki, Minsk, 220013, Belarus'.

5. Abdrakhimov RR, Sapozhnikov SB, Sinitsin VV (1984) Sensory davleniya i temperatury na osnove suspenzii epoksidnoy smoly i uglerodnykh nanotrubok. Vestnik YuurGU. Seriya «Komp'yuternye tekhnologii, upravlenie, radioelektronika» UDK 621.3.084.2; 621.3.082
6. Bortnikov VG (2002) proizvodstvo izdeliy iz plasticheskikh mass: Uchebnoe posobie dlya vuzov v trekh tomakh. Tom 2. Tekhnologiya pererabotki plasticheskikh mass. Kazan': Izd-vo «Dom pechati». - 2002. - 399 p.

7. (2016) Klassifikatsiya kompozitov http://medbe.ru/materials/stomatologicheskoematerialovedenie/klassifikatsiya-kompozitov/ Available: (Accessed: 10.02.2016).

8. (2004) Uspekhi v oblasti fiziko-khimii polimerov: Sb. obzornykh statey/ Redkol.: G.E. Zaikov i dr. - Moscow: Khimiya, 2004. - 692 p.: il. - (Panorama sovremennoy khimii Rossii). - ISBN 5-98109-009-X: B. ts. Bibliogr. V kontse otd. st.

9. (2004) Osnovy promyshlennogo sinteza, svoystva i primenenie plasticheskikh mass: Ucheb. posobie/ V.M.Zinov'ev,V.S.Sukhinin. Perm' : [b. i.], 2004. - 208 p. B. ts. V nadzag.: Perm. gos. tekhn. un-t.Bibliogr.: p. 208 (13 nazv.)

10. (2004) Khimiya i fizika polimerov so spetsial'nymi svoystvami: Ucheb. posobie. Volgograd: RPK Politekhnik Ch. 2. - 2004. - 63 p.: il. - ISBN 5-230-04288-5 : B. ts. Bibliogr.: s. 63 (14 nazv.). 